\title{
O riginal studies
}

\section{Predictors of 10-year macrovascular and overall mortality in patients with NIDDM: the Munich General Practitioner Project}

\author{
E .Standl ${ }^{1}$, B. B alletshofer ${ }^{1}$, B . D ahl' ${ }^{1}$, B . Weichenhain', , H .Stiegler ${ }^{2}$, A . H örmann ${ }^{3}$, R . H olle ${ }^{3}$ \\ ${ }^{1} \mathrm{D}$ epartment of E ndocrinology, City H ospital Schwabing, and Institute of D iabetes R esearch, M unich, G ermany \\ 2 D epartment of A ngiology, City H ospital Schwabing, M unich, G ermany \\ ${ }^{3}$ Institute for M edical Informatics and System R esearch, M unich, G ermany
}

Summary The 10-year follow-up of the M unich G eneral Practitioner Project was designed as a long-term prospective study to evaluate factors predicting macrovascular and overall mortality in a random cohort of non-insulin-dependent diabetic (NIDDM) patients. Of the original 290 patients ( 103 males, $187 \mathrm{fe}$ males, median age 65 years) $92.5 \%$ could be assessed, 103 subjects had died, 58 from macrovascular causes. In an univariate analysis of baseline data, deceased patients, and especially those who died from macrovascular causes had significantly higher fasting blood glucose, $\mathrm{H} \mathrm{bA}_{1 c}$, von Willebrand-factor protein, urine albumin excretion, and serum $\beta_{2}$-microglobulin, were significantly older, exhibited significantly more ischaemic heart disease (abnormal ECG M innesota codes), carotid artery and peripheral vascular disease (both determined by ultrasound-D oppler), and had significantly inferior knowledge about diabetes and its treatment. No significant differences were seen for gender, blood pressure, smoking, total cholesterol, triglycerides, HDL-cholesterol, or the use of antidiabetic, antihypertensive or coronary drugs. In a multiple logistic regression analysis, the risk factors for macrovascular death were age, $\mathrm{HbA}_{1 c}$ and von Willebrand-factor protein. When baseline macrovascular disease was taken into account, carotid artery disease was also a determinant. The main variables from the metabolic syndrome (blood pressure, dyslipidaemia, body mass index) did not enter a multiple logistic regression analysis. The data suggest that age and haemoglobin $\mathrm{A}_{1 c}$ are major determinants, and that in addition von Willebrand-factor associated endothelial damage is a risk factor for macrovascular mortality in NID D M patients. [D iabetologia (1996) 39: 15401545]

Keywords Non-insulin-dependent diabetes mellitus, mortality, macrovascular mortality, von Willebrandfactor, urine albumin excretion, $\mathrm{HbA}_{1 c}$, blood pressure, lipids.
Non-insulin-dependent diabetes mellitus (NIDDM) is associated with increased cardiovascular mortality in white European and other westernized populations [1-6]. A recent study from former $E$ ast B erlin, where diabetes was a centrally registered disease, indicated that the loss of life of NIDDM patients

Corresponding author: D r. E . Standl, D epartment of E ndocrinology, City H ospital Schwabing, and Institute of D iabetes R esearch, Koelner Platz 1, D-80804 M unich, Germany

A bbreviations: UAE, U rine albumin excretion; vWF protein, von Willebrand-factor protein; BM I, body mass index; TG, triglycerides; $\beta_{2}-\mathrm{MG}, \beta_{2}$-microglobulin; NIDDM, non-insulindependent diabetes mellitus; WHO, World Health Organisation. diagnosed before age 70 years was about $30 \%$ of the further life expectancy without diabetes [6]. A pproximately $60 \%$ of mortality is from cardiovascular or other macrovascular complications [2]. The risk factors responsible for the excessive macrovascular mortality and morbidity have not been well defined. It is thought the classical cardiovascular risk parameters, i.e. hypertension, hypercholesterolaemia, and smoking, must be involved [1, 4, 7-10], and increased urine albumin excretion has been incriminated by a number of studies [11-17]. The Diabetes Control and Complications Trial [18] and studies in NIDDM patients, have directed attention to the potential importance of metabolic control also in patients with NID DM [8, 9, 17, 19-21]. A bnormal coagulation 
factors, endothelial proteins, platelet function, and fibrinolysis may play a role [22].

In the $\mathrm{M}$ unich $\mathrm{G}$ eneral Practitioner Project, a defined cohort of NID D M patients living in the G reater M unich A rea launched in 1984/1985, many potential risk factors were assessed, together with macrovascular disease [9, 16, 23]. A long-term study with 10-year follow-up was planned to evaluate factors at baseline predicting the outcome in terms of macrovascular and all-cause mortality in patients with NIDDM.

\section{Subjects and methods}

Study cohort. The Munich General Practitioner Project has been described in detail previously [9, 16, 23, 24]. Briefly, 314 patients were selected for further investigation and follow-up by a random procedure (approximately 1 in 5) from a representative sample of 1512 patients with NIDDM below age 76 years as seen in 22 non-specialized, primary medical care practices, at the beginning of the project in 1984/1985. Twenty-four of these patients declined more complex investigations at baseline, therefore, 290 were enrolled at the start of the study ( 103 men, 187 women, median aged 65 years, interquartile range $59-70$ years, duration of diabetes $0-21$ years with a median of 8 years). The characteristics of the baseline group ( $57 \%$ treated with oral agents, $9 \%$ with insulin, the rest on diet alone) with a median $\mathrm{HbA}_{1 \mathrm{c}}$ of $7.9 \%$ have been published [16, 23]. This group exhibited similarities to N I D D M patients of the former G erman D emocratic R epublic where central registration of all diabetic subjects was compulsory [25]. To ensure long-term observation, the following exclusion criteria have been used in the project at entry: age over 75 years, serum creatinine over $177 \mu \mathrm{mol} / \mathrm{l}$, apparent malignancy, advanced cardiovascular complications (gangrene, amputations, myocardial infarction during the preceding year, decompensated cardiac insufficiency or cerebral infarction). Diagnosis of NIDDM was made according to World $\mathrm{H}$ ealth Organisation (WH O) criteria [26] by the local primary care physician and informed consent was obtained from each patient prior to the study, which was approved by the local ethical committee and performed in accordance with the principles of the $D$ eclaration of $\mathrm{H}$ elsinki.

E valuation of risk markers and macrovascular disease was performed at baseline. A part from a complete history and physical examination, blood pressure was measured on both arms under resting conditions three times at 2-min intervals with the lowest reading being taken for the classification of hypertension according to the WHO criteria $(>160 / 95 \mathrm{~mm} \mathrm{H}$ ). I schaemic heart disease was assessed by a 12-lead E CG using the Whitehall criteria [27] of the M innesota coding system (criteria: I 1-3, IV 1-3, V 1-2, and VII 1). E ctopic beats, sinus tachycardia or bradycardia were not considered in the rating system. Peripheral vascular disease was evaluated by the determination of blood pressure at all four extremities, i. e. at the ankle level of the lower limbs and at the upper arms using an ultrasound-D oppler device. This examination was performed after a rest of $15 \mathrm{~min}$, and a leg-arm difference of less than $10 \mathrm{~mm} \mathrm{H}$ g was considered as a pathological result [28]. To exclude false-negative results due to medial calcification of the Moenckeberg type, a Doppler-signal wave form was also recorded. M edial calcification was assumed when the normally triphasic Doppler-signal wave form was non-functionally monophasic, widened and with reduced amplitude despite a normal D oppler index [29]. For the assessment of extracranial cerebrovascular disease, a directional continuous wave ultrasound-D oppler examination of the carotid arteries was carried out. Stenoses of more than $50 \%$ and/or obliterations were defined as carotid artery disease. Finally, relative body weight was recorded as body mass index $\left(\mathrm{kg} / \mathrm{m}^{2}\right)$. Patients' knowledge about diabetes and its appropriate treatment was assessed by a multiple choice questionnaire and rated as the number of correct answers out of the total of 21 questions.

The first morning urine sample was examined for albuminuria by means of a radioimmunoassay (Pharmacia, Freiburg, Germany) with a detection threshold of $0.4 \mathrm{mg} / \mathrm{l}$. The urine sample was also screened for glycosuria and for urinary tract infection, i. e. bacteriuria, leucocyturia, erythrocyturia. Venous blood was drawn after an overnight fast without stasis and vonWillebrand-factor protein (VWF protein) was determined in plasma by quantitative immune electrophoresis [30] and expressed as percentage of a standard reference $(100 \%)$. Blood glucose and $\mathrm{HbA}_{1 \mathrm{c}}$ were assayed in capillary blood, and total cholesterol, HDL-cholesterol, triglycerides, creatinine, and $\beta_{2}$-microglobulin in serum by standard procedures [31].

Follow-up and definition of outcome. Follow-up investigations have been performed 3 and 5 years after the baseline examination and results published previously $[9,16]$. The present study was designed as a follow-up on 10-year (macrovascular) mortality. In spring 1995, all participants were contacted and data of $92.5 \%$ of the original cohort of 290 patients at baseline could be obtained for analysis through the patients themselves, their primary care physicians or the local administration authorities. O nly 22 patients were lost to follow-up but their baseline characteristics did not differ from the rest of the cohort. For patients who had died, cause of death was assessed from death certificates, hospital records and autopsy reports by means of a standardized questionnaire. $O f$ the 103 deceased patients 27 were examined by autopsy, 78 died in hospital. Causes of death were classified as clearly due to macrovascular disease, or confirmed other reasons or unknown. Criteria for macrovascular death (cardiovascular and/or cerebrovascular in all instances except one ruptured aneurysm of the abdominal aorta) included confirmation of the diagnosis on the death certificate or the hospital record or an autopsy report confirming the presence of macrovascular disease as cause of death and the absence of non-macrovascular disease that could explain death.

\section{Statistical analysis}

Statistical analysis was done using the SPSS/PC package [32]. Results are given as median values + interquartile ranges or as percentages. Differences were assessed by chi-square or Wilcoxon test as appropriate. Comparisons between survivors and deceased patients or deceased patients from macrovascular disease, respectively, were corrected for age by using logistic, regression analysis with age as a covariate. Since lossto-follow-up was small (approximately 7\%), stepwise logistic regression analysis was performed using all variables significantly different in univariate analysis together with the main markers of the metabolic syndrome, hypertension, dyslipoproteinaemia, and body mass index, and with macrovascular death or all-cause mortality as the outcome [33]. This analysis was done with and without inclusion of ischaemic heart disease, peripheral vascular disease, and carotid artery disease present at baseline to evaluate the impact of pre-existing macrovascular disease. In addition, a multiple logistic regression analysis was also performed, including only the main 
Table 1. Clinical characteristics at baseline in survivors vs deceased patients vs deceased from macrovascular deaths (age corrected comparison using logistic regression analysis with age as a covariate)

\begin{tabular}{|c|c|c|c|}
\hline $\begin{array}{l}\text { Outcome } \\
\mathrm{n}\end{array}$ & $\begin{array}{l}\text { Survivors } \\
165\end{array}$ & $\begin{array}{l}\text { A II deceased } \\
\text { patients } \\
103\end{array}$ & $\begin{array}{l}\text { M acrovascular } \\
\text { deaths only } \\
58\end{array}$ \\
\hline BMI $\left(\mathrm{kg} / \mathrm{m}^{2}\right)^{\mathrm{a}}$ & $27.7(25.5-30.8)$ & $26.7(24.1-29.6)$ & $26.3(23.9-29.9)$ \\
\hline Diabetes duration (years) ${ }^{a}$ & $7(2-11)$ & $9(2-14)$ & $8(2-13)$ \\
\hline $\begin{array}{l}\text { Diabetes knowledge } \\
\text { (no. correct answers) }\end{array}$ & $12 / 21$ & $10 / 21^{c}$ & $10 / 21^{c}$ \\
\hline $\begin{array}{l}\text { Ischaemic heart } \\
\text { disease }(\%)\end{array}$ & 34 & $58^{b}$ & $61^{b}$ \\
\hline $\begin{array}{l}\text { Carotid artery } \\
\text { disease }(\%)\end{array}$ & 4.3 & $15.3^{b}$ & $18.9^{b}$ \\
\hline $\begin{array}{l}\text { Peripheral vascular } \\
\text { disease }(\%)\end{array}$ & 33 & $53^{b}$ & $60^{b}$ \\
\hline
\end{tabular}

${ }^{a}$ M edian values (IQR ); ${ }^{b} p<0.003 ;{ }^{c} p<0.05$ (vs survivors)

markers of the metabolic syndrome, hypertension, dyslipidaemia, body mass index and $\mathrm{H} \mathrm{bA}{ }_{1 c}$, together with age. For modelling, dyslipidaemia was defined as cholesterol over 6.5 $\mathrm{mmol} / \mathrm{l}$ or $\mathrm{HDL}$-cholesterol under $0.9 \mathrm{mmol} / \mathrm{l}$ or triglycerides over $2.6 \mathrm{mmol} / \mathrm{l}$.

Finally, percentage of macrovascular mortality in subgroups with and without preexisting macrovascular disease were computed in relation to tertiles of $\mathrm{HbA}_{1 \mathrm{c}}$ and $\mathrm{VWF}$-protein at baseline.

\section{Results}

Status and causes of death. O ver the 10 -year period of follow-up, 103 (38.5\% ) of the 268 re-investigated patients of the original cohort ( $92.5 \%$ ascertainment) were deceased, 58 ( $56.3 \%$ ) of whom clearly had died from macrovascular causes and $33(32 \%)$ from confirmed non-macrovascular reasons. In 12 (11.7\%) of all deaths, the cause of death could not be classified.

B aseline factors and outcome. Table 1 depicts the clinical baseline characteristics of the 165 patients alive, the 103 deaths and the 58 macrovascular deaths. Patients with macrovascular deaths and all-cause deaths were significantly older than survivors at the beginning of the study in 1984/1985 (median plus interquartile ranges: $68,64-72$ years vs $67,64-72$ years vs 63 , 56-69 years, $p<0.003)$. A ge-corrected comparison indicated that deceased patients had a similar body weight and known duration of diabetes, but significantly more ischaemic heart disease, carotid artery disease, and peripheral vascular disease at baseline and showed a significantly inferior knowledge about diabetes and its treatment. A s might be expected differences were more marked for macrovascular deaths than for all-cause deaths compared to the survivors. No significant differences were found as to gender, antidiabetic therapy at baseline, the use of common antihypertensive and coronary drugs, e. g. beta blockers, Ca-antagonists, nitrates, platelet aggregation inhibitors and smoking. The prevalence of the various antihypertensive and coronary drugs, and for active smoking at baseline 1984/1985, was low and from $3.5 \%$ for antiplatelet drugs to $16 \%$ for active smoking.

Table 2, displays the age-corrected comparison of potential risk factors for macrovascular complications in the same three groups of patients at baseline. Compared to survivors, deceased patients and especially patients with macrovascular deaths showed significantly higher values for fasting blood glucose, $\mathrm{HbA}_{1 \mathrm{c}}$, vW F protein, urine albumin excretion, $\beta_{2}$-microglobulin in serum and serum creatinine. No differences were observed for blood pressure and lipid parameters.

Multivariate analysis. Stepwise logistic regression analysis of factors influencing macrovascular death as outcome indicated age, $\mathrm{H} \mathrm{bA}{ }_{1 c}$ and $\mathrm{vWF}$ protein as significant independent determinants of macrovascular death (Table 3). When co-existing macrovascular disease at baseline (ischaemic heart, carotid artery, and peripheral vascular disease) were incorporated into the model, again $\mathrm{HbA}_{1 c}$, vWF protein, and in addition carotid artery disease emerged as significant predictors of macrovascular mortality besides age (Table 3 ). A s to all-cause deaths as outcome, the pattern of risk variables in stepwise logistic regression analysis was less clear, but again included age $(p=0.004)$; vW F protein $(p=0.005)$, carotid artery disease $(p=0.008)$, glycaemic control as measured by fasting blood glucose $(p=0.04), \beta_{2}$-microglobulin $(p=0.05)$ and urinary albumin excretion ( $p=0.05$ ) as significant predictors, in the two models applied.

Restricting multiple regression analysis for macrovascular death as outcome to the main markers of the metabolic syndrome at baseline (Table 4) indicated that only $\mathrm{H} \mathrm{bA}_{1 \mathrm{c}}$ - besides age - was of significant importance. 
Table 2. Potential cardiovascular risk factors at baseline in survivors vs deceased patients vs deceased from vascular deaths (age corrected comparison using logistic regression analysis with age as a covariate)

\begin{tabular}{|c|c|c|c|}
\hline Outcome & $\begin{array}{l}\text { Survivors } \\
165\end{array}$ & $\begin{array}{l}\text { A II deceased } \\
\text { patients } \\
103\end{array}$ & $\begin{array}{l}\text { M acrovascular } \\
\text { deaths only } \\
58\end{array}$ \\
\hline$\overline{\text { Systolic BP (mm H g) }}$ & $150(130-170)$ & $150(140-170)$ & $150(130-170)$ \\
\hline D iastolic BP ( $\mathrm{mm} \mathrm{H} \mathrm{g})$ & $85(80-95)$ & $85(80-92)$ & $85(80-95)$ \\
\hline Fasting blood glucose ( $\mathrm{mmol} / \mathrm{l})$ & $7.3(5.7-10.8)$ & $9.2(6.4-12.2)^{a}$ & $9.7(7.2-12.1)^{\mathrm{a}}$ \\
\hline $\mathrm{HbA}_{1 \mathrm{c}}(\%)$ & $7.7(6.3-9.0)$ & $8.1(6.9-9.6)^{b}$ & $8.2(7.1-10.0)^{\mathrm{a}}$ \\
\hline Cholesterol ( $\mathrm{mmol} / \mathrm{l})$ & $5.8(5.0-6.8)$ & $6.0(5.0-7.1)$ & $6.0(5.4-6.9)$ \\
\hline Triglycerides (mmol/l) & $2.6(1.7-4.3)$ & $2.7(1.7-4.3)$ & $2.7(1.8-4.3)$ \\
\hline HDL cholesterol (mmol/l) & $1.1(0.9-1.3)$ & $1.0(0.9-1.3)$ & $1.0(0.9-1.2)$ \\
\hline vWF protein (\%) & $175(120-271)$ & $222(172-320)^{a}$ & $240(183-351)^{a}$ \\
\hline urinary albumin excretion (mg/dl) & $9.6(4.5-19)$ & $21(5.6-86)^{\mathrm{a}}$ & $21(6.8-109)^{\mathrm{a}}$ \\
\hline$\beta_{2}-\mathrm{M} \mathrm{G}(\mathrm{mg} / \mathrm{dl})$ & $1.7(1.4-2.1)$ & $1.9(1.5-2.5)^{b}$ & $1.9(1.5-2.6)^{b}$ \\
\hline Serum-creatinine $(\mu \mathrm{mol} / \mathrm{l})$ & $89(80-106)$ & $97(80-115)^{b}$ & $97(80-124)^{b}$ \\
\hline
\end{tabular}

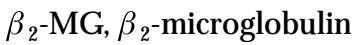

Median values (IQR) ${ }^{a} \mathrm{p}<0.01 ;{ }^{b} \mathrm{p}<0.05$ (vs survivors)

Table 3. Stepwise logistic regression analysis of selected risk variables (significantly different in univariate analysis plus markers of the metabolic syndrome) for the prediction of macrovascular mortality in NID D M patients $(n=223)$

\begin{tabular}{lllcl}
\hline Variable & B & S.E. & Wald-chi $^{2}$ & p-value \\
\hline A ge (years) & -0.08 & 0.03 & 9.11 & 0.002 \\
H bA $_{1 c}(\%)$ & -0.18 & 0.09 & 4.36 & 0.03 \\
vW F protein (\%) & -0.004 & 0.002 & 7.16 & 0.007 \\
Constant & 8.59 & 2.01 & 18.20 & 0.000
\end{tabular}

A nd of the same selected risk variables plus pre-existing macrovascular disease for the prediction of macrovascular mortality in NID D M patients $(n=223)$

$\begin{array}{lllll}\text { A ge (years) } & -0.06 & 0.03 & 5.47 & 0.02 \\ \mathrm{H} \mathrm{bA}_{1 \mathrm{lc}}(\%) & -0.19 & 0.09 & 4.37 & 0.04 \\ \text { vW p protein (\%) } & -0.003 & 0.002 & 4.53 & 0.03 \\ \text { Carotid artery } & & & & \\ \text { disease } & 1.63 & 0.58 & 7.87 & 0.005 \\ \text { Constant } & 4.39 & 2.30 & 3.62 & 0.05\end{array}$

N on significant: blood pressure, dyslipidaemia ${ }^{a}$, body mass index, fasting blood glucose serum creatinine, urinary albumin excretion, $\beta_{2}$-microglobulin, ischaemic heart disease, peripheral vascular disease

a for definition see text

Finally, Figure 1 demonstrates frequencies of macrovascular mortality with higher tertiles of $\mathrm{H} \mathrm{bA}_{1 \mathrm{c}}$ and of VWF protein. A s can be seen, there is a steep increase of macrovascular mortality with higher tertiles, even when pre-existing macrovascular disease was taken into account.

\section{Discussion}

This is a 10-year prospective study to evaluate among most of the presently known or suspected risk factors - significant determinants of macrovascular and all-cause mortality in a cohort of well-characterised NIDD M patients. By stepwise logistic regression analysis it showed that glycaemic control as measured by $\mathrm{HbA}_{1 c}$ and circulating concentrations of the endothelial protein, vWF protein, besides age, were risk factors for the macrovascular mortality outcome in NIDDM patients. These findings persisted, even when co-existing macrovascular disease at baseline, i. e. coronary, carotid, and peripheral vascular disease were taken into account which all had been assessed by appropriate techniques at entry. A pplying this approach, however, it was demonstrated that together with $\mathrm{HbA}$ ic and VWF protein the presence of carotid artery disease emerged as a significant independent determinant of macrovascular death. Similarly, the independent effect of $\mathrm{HbA}_{1 c}$ and VWF protein, was apparent with and without considering macrovascular disease at entry when frequency of macrovascular deaths were computed in relation to tertiles of $\mathrm{H} \mathrm{bA}_{1 \mathrm{c}}$ and VWF protein at baseline (Fig. 1). When the main markers of the metabolic syndrome were incorporated into multiple logistic analysis, $\mathrm{HbA}_{1 \mathrm{c}}$ and age remained the major predictors of macrovascular death. In terms of all-cause mortality, results of multivariate analysis were less clear cut, but were in keeping with the observations, obtained for macrovascular deaths.

Debate has recently been intensified as to how much glycaemic control matters not only for the outcome of patients with IDDM , but also for those with NID D M. So far, reports from two Scandinavian studies in 1994 and $1995[19,20]$ have provided evidence that long-term cardiovascular mortality of NIDDM patients may be significantly associated with increasing tertiles of the baseline $\mathrm{HbA}_{1 \mathrm{c}}$ or fasting blood glucose. The present study has shown that $\mathrm{H} \mathrm{bA}_{1 c}$ was predictive for macrovascular mortality in a multivariate 
Table 4. M ultiple logistic regression analysis of markers of the metabolic syndrome for the prediction of macrovascular mortality in NIDDM patients $(n=223)$

\begin{tabular}{lllll}
\hline Variable & B & S.E. & Wald-chi $^{2}$ & p-value \\
\hline A ge (years) & -0.08 & 0.02 & 17.36 & 0.001 \\
Hypertension & -0.04 & 0.29 & 0.01 & N.S. \\
Dyslipidaemia $^{a}$ & -0.05 & 0.29 & 0.03 & N.S. \\
${\text { B M I }\left(\mathrm{kg} / \mathrm{m}^{2}\right)}^{\text {H bA }}{ }_{1 \mathrm{c}}(\%)$ & -0.05 & 0.03 & 1.90 & N.S. \\
Constant & -0.16 & 0.07 & 4.94 & 0.02 \\
\hline
\end{tabular}

N.S., N on significant; ${ }^{a}$ for definition see text
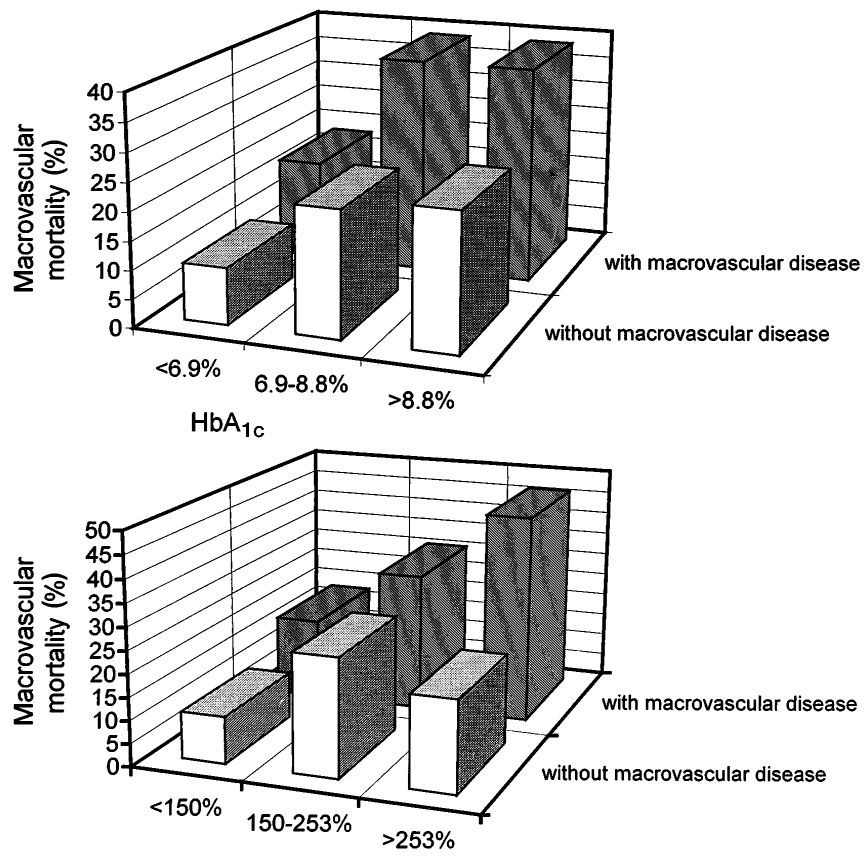

von-Willebrandfactor protein

Fig. 1. 10-year macrovascular mortality (\%) of NIDDM patients in relation to $\mathrm{HbA}_{1 \mathrm{c}}$ and von Willebrand-factor protein at baseline

analysis. Final proof for the impact of glycaemic control on the macrovascular or overall outcome of NIDDM patients, however, has to be awaited from specifically planned intervention studies, e.g. the UKPDS [34].

Serum vWF protein was found to be a risk factor for macrovascular mortality. Previously, vW F protein has predominantly been discussed in relation to diabetic microangiopathy $[22,35]$. On the other hand, VW F protein has been shown of correlate closely with platelet aggregation in diabetic patients and to precede structural vascular changes in experimental and human diabetes [35, 36]. VW F protein is essential for normal platelet adhesion to the vessel wall and is mainly produced by endothelial cells [22]. Increased circulating levels of vW F protein have been thought to reflect endothelial damage and signify an active crosstalk of the endothelium with platelets, especially when activation molecules such as CD 62 are expressed on the platelet surface, as is quite often the case in diabetes [22]. In the present study, vWF protein was associated with macrovascular mortality both in the presence and absence of established macrovascular disease at entry into the study.

Surprisingly little influence of the classical cardiovascular risk factors, i.e. smoking, hypertension, and dyslipidaemia including hypercholesterolaemia, was seen on the 10-year outcome in the M unich $\mathrm{G}$ eneral Practitioner Project. This may have specific reasons, since the prevalence of smoking was only $16 \%$ at baseline, and $46 \%$ of all subjects were al ready under treatment with antihypertensive drugs at entry to the study and $75 \%$ had a blood pressure $170 / 95 \mathrm{~mm} \mathrm{H}$ g or less at recruitment (Table 2). Total cholesterol and HDL cholesterol were similar to the general population at median age 65 in Germany and $75 \%$ of all patients had a total cholesterol of less than $7.0 \mathrm{mmol} / \mathrm{l}$ (Table 2). U nfortunately, neither small dense LD L nor lipoprotein (a) were measured. O $\mathrm{n}$ the other hand other long-term studies in NID D M have also recently failed to demonstrate a significant impact of blood pressure [17], lipids [8], or smoking [4, 8] on mortality, so there is uncertainty as to the importance of these factors in NIDDM populations. However, these studies have been moderately small, and they do not disprove the influence of the classical cardiovascular factors in NIDDM. These were shown to be operative when non-diabetic and diabetic populations were compared, e. g. in the Framingham [37] M ultiple R isk Factor Intervention Trial [1], and in one of the Scandinavian studies [10]. The present study indicates a role for $\mathrm{H} \mathrm{bA}_{1 \mathrm{c}}$ and $\mathrm{VW} \mathrm{F}$ protein in determining macrovascular mortality in NID D M patients.

A cknowledgements. The invaluable and instrumental assistance of M rs. G. Wochermaier is greatly appreciated. The study was supported by a grant of the Bundesministerium für Forschung und Technologie, B onn, Germany.

\section{References}

1. Stamler J, Vaccaro O, Neaton J D, Wentworth D (1993) D iabetes, other risk factors, and 12-yr cardiovascular mortality for men screened in the Multiple Risk Factor Intervention Trial. D iabetes Care 16: 434-444

2. Panzram G (1987) M ortality and survival in type 2 (non-insulin-dependent) diabetes mellitus. Diabetologia 30: 123131

3. Laakso $M$, Rönnemaa $T$, Pyörälä $K$, Kallio $P$, Punka $P$, Penttila I (1988) A therosclerotic vascular disease and its risk factors in non-insulin-dependent and non-diabetic subjects in Finland. D iabetes Care 11: 449-463

4. $H$ anefeld M, Fischer S, Schmechel H (1991) D iabetes Intervention Study: multiple intervention trial in newly diagnosed NIDDM . D iabetes Care 14: 308-317

5. Singer DE, Nathan DM, A nderson KM, Wilson PWF, Evans JC (1992) A ssociation of $\mathrm{HbA}_{1 c}$ with prevalent 
cardiovascular disease in the original cohort of the Framingham H eart Study. D iabetes 41: 202-208

6. Thoelke H, Meusel K (1994) Zur Überlebensdauer von Typ-II-D iabetikern. Ergebnisse einer 20-jährigen Followup-Studie in Berlin O st. D iskussionsbeiträge zur G esundheitsforschung, Senatsverwaltung für G esundheit, B erlin, Papier 19, pp 1-33

7. Standl E (1995) Hyperinsulinemia and atherosclerosis. J Clin Invest Med 18: 261-266

8. Janka H U, B alletshofer B, Becker A, G ick NR, H artmann J, Möckelmann S, M öltner A (1992) The metabolic syndrome as a potent risk factor for premature death in NIDDM: The Schwabing Study - 9 year follow up. Diab Stoffw 1: 2-7

9. Stiegler H, Standl E, Schulz K, Roth R, Lehmacher W (1993) Frequency, risk profile and mortality of a random sample of albuminuric type 2 diabetic patients. A 5 year prospective study in general practice. D iab Stoffw 2: 62-67

10. U usitupa MIJ, N iskanen LK, Siitonen O, Voutilainen E, Pyörälä K (1993) Ten-year cardiovascular mortality in relation to risk factors and abnormalities in lipoprotein composition in type 2 (non-insulin-dependent) diabetic and nondiabetic sujects. D iabetologia 36: 1175-1184

11. Mogensen CE (1984) Microalbuminuria predicts clinical proteinuria and early mortality in maturity-onset diabetes. N Engl J Med 310: 356-360

12. Jarrett TJ, V iberti G C, A rgyropoulos A, H ill RD, M ahmud U, M urrells R J (1984) M icroalbuminuria predicts mortality in non-insulin-dependent diabetes. D iabet M ed 1: 17-19

13. Schmitz A , Vaeth M (1988) M icroalbuminuria: a major risk factor in non-insulin dependent diabetes: a 10 year followup of 503 patients. D iabet M ed 5: 126-134

14. Mattock M B, M orrish NJ, V iberti GC, K een H, Fitzgerald A P, Jackson $G$ (1992) Prospective study of microalbuminuria as a predictor of mortality in NIDDM . Diabetes 41 : 736- 741

15. Neil A, Hawkins $M$, Potok $M$, Thorogood $M$, Cohen D, Mann J (1993) A prospective population-based study of microalbuminuria as a predictor of mortality in NIDDM. Diabetes Care 16: 994-1003

16. Stiegler $H$, Stand $E$, Schulz K, R oth R, Lehmacher W (1992) M orbidity, mortality and albuminuria in type 2 diabetic patients: a three-year prospective study of a random cohort in general practice. D iabet M ed 9: 646-653

17. M cL eod J M , L utale J, M arshall SM (1995) A lbumin excretion and vascular deaths in NID D M . D iabetologia 38: 610616

18. The Diabetes Control and Complications Trail R esearch $G$ roup (1993) The effect of intensive treatment of diabetes on the development of long term complications in insulin dependent diabetes mellitus. N E ngl J M ed 329: 977-986

19. Kuusisto J, Mykkänen L, Pyörälä K, Laakso M (1994) NIDDM and its metabolic control predict coronary heart disease in elderly subjects. D iabetes 43: 960-967

20. U usitupa MIJ, Niskanen LK (1995) Hyperglycemia and cardiovascular risk in NID D M. D iabetes Care 18: 884-885
21. Selby J V, Z hang D (1995) R isk factors for lower extremity amputation in persons with diabetes. Diabetes Care 18: 509-516

22. Ingerslev J (1995) Research methodologies in measurement of platelet function, endothelial proteins, coagulation factors and fibrinolysis. In: M ogensen CE, Standl E (eds) R esearch methodologies in human diabetes. Part 2. De G ruyter, B erlin N ew York pp 125-146

23. StandI R, Stiegler H, R ebell B et al. (1990) D er Typ-II-Diabetes in der Praxis des niedergelassenen A rztes, Konzept einer zentrumsgestützten B etreuung und E rgebnisse einer Stichprobenerhebung im Großraum München. A kt Endokr Stoffw 11: 222-227

24. Standl E, Stiegler H (1993) M icroalbuminuria in a random cohort of recently diagnosed type 2 (non-insulin-dependent) diabetic patients living in the $G$ reater $M$ unich $A$ rea. D iabetologia 36: 1017-1020

25. M ichaelis D, Jutzi E (1991) Epidemiologie des Diabetes mellitus in der B evölkerung der ehemaligen D D R . A Itersund geschlechtsspezifische Inzidenz- und Prävalenztrends im Z eitraum 1960-1987. Z K lin M ed 46: 59-66

26. WHO Study Group (1985) D iabetes mellitus. Technical report series 727. W H O, G eneva pp 1-113

27. Fuller JH, Shipley M J, Rose G, Jarrett RJ, K een H (1980) Coronary heart disease risk and impaired glucose tolerance: the Whitehall study. L ancet I: 1373-1376

28. Köhler M , R oth FJ, EI-M amoun B (1982) U ntersuchungen über die Spezifität der peripheren systolischen D ruckmessung mit der U Itraschall-D oppler-Technik an gesunden angiographierten Extremitäten. Z K ardiol 71: 156-162

29. K riessmann A, Bollinger A, K eller $\mathrm{H}$ [eds] (1982) Praxis der D oppler-Sonographie. Thieme, Stuttgart pp 1-51

30. Zimmermann TS, H oyer LW, Dickson L, E dington TS (1975) D etermination of the von Willebrand's disease antigen (factor V III related antigen) in plasma by quantitative immune electrophoresis. J L ab Clin M ed 86: 152-159

31. B ergmeyer HU [ed] (1985) M ethods of enzymatic analysis. 3rd edn. VCH Verlagsgemeinschaft, Weinheim

32. Morris MJ (1986) SPSS/PC+: SPSS for the IBM PC/XT/ A T. SPSS inc., Chicago

33. Cox DR (1970) The analysis of binary data. M ethuen, L ondon

34. U K PD S Study G roup: H olman R R, Cull CA, Fox D, Turner R C (1995) U K PD S 13: R elative efficacy of randomly allocated diet, sulfonylurea, insulin or metformin in patients with newly diagnosed type 2 diabetes followed for three years. BM J 310: 83-88

35. Janka HU, Standl E, Schramm W, M ehnert H (1983) Platelet enzyme activities in diabetes mellitus in relation to endothelial damage. Diabetes 32 [Suppl 2]: 47-51

36. Stehouwer CDA, Nanta JJ P, Z eldenrust G C (1992) U rinary albumin excretion, cardiovascular disease and endothelial dysfunction in non-insulin dependent diabetes mellitus. L ancet 340: 319-323

37. K annel W B, M CG ee D L (1979) Diabetes and cardiovascular risk factors in the Framingham Study. Circulation 59: 8-13 